\title{
Student engagement: identity, motivation and community
}

\section{Book review}

\author{
Nygaard, C., Brand, S., Bartholomew, P. and Millard, L. (2013) Student engagement: \\ identity, motivation and community. Faringdon, Oxfordshire, UK: Libri Publishing, \\ pp.310, £42.00, ISBN 978-1-90747165-0.
}

This book is remarkable for a number of reasons. Firstly, unlike many edited collections, it is not a loosely constructed arrangement consisting of research conducted in widely varied contexts, but it instead appears to be the embodiment of a commonly held vision of a university as a site where student engagement is encouraged and made possible via structured opportunities for students and staff to work together in the pursuit of learning.

The book is also remarkable because it represents such a rapid process from conception to production - some 14 months from initial meeting to publication. The book was the result of collaboration between The International Academic Association for the Enhancement of Learning and Teaching (LIHE), the Centre for Enhancement of Learning and Teaching (CELT) at Birmingham City University, the Student's Union at Birmingham City University and Libri Publishing. This goes to show what is possible when organisations work closely together, and may form a model for others to emulate.

The book aims to present an account of the early stages of Birmingham City University's initiative to promote a partnership model for higher education, rather than a consumerist one. The manner in which the book was created and produced certainly acts as an object lesson in how a dedicated group of staff and students can work together to create something worth-while, and at this level the book delivers in both form and content.

The book contains a series of sixteen chapters: an initial chapter which addresses the general issue of 'Why student engagement matters' and fifteen subsequent chapters, each of which outlines and discusses various initiatives carried out at Birmingham City University in the name of promoting student engagement. 
The title of the book suggests that student engagement is a major theme, and whilst this is certainly a key theme in the articles it contains, the perspective it offers on engagement is ultimately disappointing. There is a lack of clarity on the question of what students are engaging with, where some of the articles in the collection seem to confuse engagement of students with their tutors and the university with engagement of students with the process of education.

The book will appeal to anyone who is interested in ways to promote engagement of students and staff in higher education. In particular the book should appeal to learning developers, those with management roles, such as Faculty Deans, and others responsible for the student experience. However, despite the interesting and worthy nature of the volume, it is not a book for those seeking definitive answers, instead providing a selection of interesting examples of attempts to enhance student engagement. These examples may be useful in suggesting lines of enquiry and action, although, as will be argued below, not all of those within this volume are as promising as the authors suggest.

Each chapter is written by a different team which means that the style and content of each chapter is necessarily varied; however, each chapter is well-written and easy to understand. The applied nature of the initiatives reported upon helps to make sure that the emphasis is upon practical matters, yet each chapter is set within an appropriate theoretical context. The book is roughly divided into three key themes: identity, motivation and community, and these are presented in chapter order, although without any markers between sections.

The key strength of the book lies in the variety of the projects it describes and the ability that this variety and the style of writing affords the reader to dip in and out, rather like sampling a box of chocolates. As might be expected, not all initiatives were complete successes, and this in itself provides useful context, with each contribution providing a platform from which to assess others and to consider and guide one's own initiatives.

The main weakness of the book is the lack of a clear theoretical framework. The introductory chapter: 'Why Student Engagement Matters' leads one to believe that Freire's (2005) Pedagogy of the Oppressed might provide a framework, and some of the chapters which follow also share this framework; however, several chapters rely instead upon Kuh's (2009, p.683) definition of student engagement as: ' ...the time and efforts students devote 
to activities that are empirically linked to desired outcomes' is used in several articles as a key part of the theoretical justification of the activities described, yet this seems rather too broad, and perhaps greater specificity would be useful.

Such broad definitions allow a wide range of activities to be classed as student engagement in this volume. These activities seem to come under perhaps three general headings which might be described as employment, involvement in governance and involvement in knowledge creation.

Chapter three describes how students were hired on a one-year placement basis as Studio Manager and Laboratory Manager in the School of Digital Media Technologies. In this chapter, employment is proposed as an example of student engagement via their use as storekeepers and other forms of technical and administrative support. This, it is proposed, helps those students chosen to better understand their lecturers and to be able to provide their fellow students with a fresh perspective upon the challenges faced by higher education. However, ultimately this form of employment seems little different from other forms of cheap labour. Benefits from such a scheme appear to include improved student engagement via the placement student 'bridging the gap between staff and students', placement students can inspire and engage other students as a role model, and 'real world vocational experience' can be gained by the placement student, or Student Partner, as they have become known. This employment-related theme is highlighted elsewhere, for example, chapter seven argues that employing students within the university leads to a number of benefits, including increased student motivation, and as 'a cost-effective method of providing vibrant new ideas and staff for the university' (p.122), and the authors go on to surmise that, although current levels of engagement-related student employment are around ten percent, they believe that the challenge is to move toward a situation where between 50 and $75 \%$ of students are employed in such a way. This logic is, I believe, flawed in three ways: first, it assumes that there are sufficient suitable roles for students to fill; second, that there will be enough students willing and able to fill those roles; and perhaps most importantly, that it is the business of a university to be employing the majority of its students in running the institution they have enrolled in to get an education. I believe that this is vocationalism gone too far. In the current economic climate, with intense competition for relatively small numbers of opportunities, it seems entirely right that universities should do what they can to provide professional level opportunities for their students, but this should not be seen as more than a 'sticking 
plaster' and it is important to remember that universities are not simply seeking to reproduce themselves, but instead to prepare students to contribute to wider society.

The second heading under which student engagement is discussed is that of academic governance, and chapter six relates how Student Advisory Boards, in which students take a much more active role in the governance of their university than they had previously been able to achieve via participation in Boards of Studies. This chapter outlines a number of positive outcomes from such Student Advisory Boards, and seems to be a superior way of promoting student engagement than does employment; however, this approach shares a weakness with the employment approach, namely that there may be a limited number of students willing and able to take up the opportunity. The authors acknowledge that those students who become involved tend to be among the most positive and confident, and they acknowledge the desire to increase involvement among other groups.

In reading the book it became apparent that any achievable and sustainable approach to promoting student engagement must occur via the essential educational purpose of the university. That is, students must be encouraged to engage with the process of education, and if necessary this may require the process to change, rather than co-opting students to shore up the existing process.

One example where larger scale engagement may be possible lies on the example of problem-based learning, where many students began to engage with the learning process in new and more intense ways; however, as noted in the article, many students did not enjoy the uncertainty associated with finding problem-owners and taking greater responsibility for their own education.

As the authors pointed out, 'problem - based Learning does not appear to be for everyone' (p.163), and it may be that engagement, of the kind sought by educators, is not for every student. This is perhaps the essential paradox: that true engagement is currently experienced by far fewer students than we would like, yet up-scaling to include all students may not be possible via the means currently employed.

Although this review has highlighted some weaknesses, this is still a very valuable contribution to the debate around what student engagement is and how to achieve it. Reading the chapters within the book has prompted me to reflect upon my own practice 
and the initiatives that I am part of, and I believe that other learning developers will also find much to reflect upon in this volume.

\section{Reviewer}

Craig Whittaker is Lead Academic Support Tutor in the Faculty of Business and Law at the University of the West of England. E-mail: craig.whittaker@uwe.ac.uk

\section{References}

Freire, P. (2005) Pedagogy of the oppressed. New York: Continuum.

Kuh, G.D. (2009) 'What student affairs professionals need to know about student engagement', Journal of College Student Development, 50(6), pp. 683-706. 